\title{
Intersphincteric Resection Is the Optimal Procedure for Very Low Rectal Cancer: Techniques, Morbidity, Oncologic and Functional Outcomes
}

\author{
Ali Zedan1, Anwar Tawfik1, Ebrahim Aboeleupn1', Asmaa Salah ${ }^{2}$, Aiat Morsy³ \\ ${ }^{1}$ Surgical Oncology Department, South Egypt Cancer Institute, Assiut University, Egypt \\ ${ }^{2}$ Radiation Oncology and Nuclear Medicine Department, South Egypt Cancer Institute, Assiut University, Egypt \\ ${ }^{3}$ Clinical Oncology and Nuclear Medicine Department, Faculty of Medicine, Assiut University, Egypt \\ Email: alizedan73@yahoo.com
}

How to cite this paper: Zedan, A., Tawfik, A., Aboeleupn, E., Salah, A. and Morsy, A. (2019) Intersphincteric Resection Is the Optimal Procedure for Very Low Rectal Cancer: Techniques, Morbidity, Oncologic and Functional Outcomes. Journal of Cancer Therapy, 10, 400-410.

https://doi.org/10.4236/jct.2019.105033

Received: January 2, 2019

Accepted: January 28, 2019

Published: May 31, 2019

Copyright ( 2019 by author(s) and Scientific Research Publishing Inc. This work is licensed under the Creative Commons Attribution International License (CC BY 4.0).

http://creativecommons.org/licenses/by/4.0/

(c) (i) Open Access

\begin{abstract}
Background: The intersphincteric resection the most extreme form of a sphincter-preserving alternative for the abdominoperineal resection. Aim of the Work: We investigated oncological, functional outcomes and morbidity after ISR. Methods: This retrospective study included 164 patients who underwent ISR with between 2010 and 2015, Male 56.1\%, Female 43.9\%, with a median age was 54.5 years, Median follow-up time was of 48 months, Average surgical time was $230 \mathrm{~min}$, Median blood loss was $700 \mathrm{~mL}$ and median hospital stay was nine days. Mean tumour size was $34 \mathrm{~mm}$. The surgical procedure through a laparotomy (72.6\%), laparoscopically (27.4\%). Neoadjuvant radiotherapy $89.6 \%$ \{long-course radiotherapy $74.4 \%$, short-course radiotherapy $15.2 \%$, neoadjuvant chemotherapy $28.7 \%$ and adjuvant chemotherapy 70.1\%. Colonic J-pouch $16.5 \%$, Transverse coloplasty $15.9 \%$, a side-to-end anastomosis $26.8 \%$ and straight coloanal anastomosis $40.9 \%$. Partial-ISR $36.6 \%$, subtotal-ISR $37.2 \%$, total-ISR $26.2 \%$, diverting ileostomy $6.7 \%$. Results: Operative mortality $1.2 \%$, morbidity $14.6 \%$ (anastomotic leakage $3.7 \%$, anastomotic stenosis $1.8 \%$, a recto-vaginal fistula $2.4 \%$ bowel obstruction $3 \%$, surgical site infection 3\%. Respiratory tract infection $1.2 \%$, local $7.9 \%$, distant recurrence $15.2 \%$, 5-year overall 79.8\%, disease-free survival 75.8\%, R0 resection $95.1 \%$. Pathologic complete response $11 \%$. Circumferential margin involvement $2.4 \%$. Median number of lymph nodes 17 . Mean distal margin 20 $\mathrm{mm}$, after 12 months Median Wexner score 6. Incontinence for (flatus 11\%, liquid $4.9 \%$, solid $4.3 \%$ ). Median bowel motions in a 24 -h were 3 . Faecal urgency $17.7 \%$. Stool fragmentation $18.9 \%$. Difficult evacuation $17.7 \%$, lifestyle
\end{abstract}


alteration $14.6 \%$. Difficulty Feces/flatus discrimination 43.3\%. Nocturnal soiling in $17.1 \%$. Daytime soiling $11 \%$. Pad wearing $23.8 \%$. Anti-diarrhoea medication loperamide $14 \%$. Conclusion: ISR is a feasible surgical procedure for low rectal cancer. Oncologic and functional, outcomes after are acceptable.

\section{Keywords}

Intersphincteric Resection, ISR, Cancer Rectum, Functional Outcomes, Oncologic Outcomes

\section{Introduction}

Abdominoperineal resection (APR) since miles 1908 for distal rectal cancer associated with high local recurrence rates, permanent colostomy has a poor quality of life, now indicated only in External sphincter infiltration. Total mesorectal excision (TME) in 1982 by Heald consider gold standard of surgical technique for rectal cancer which results in improved survival and reduced local recurrence [1] [2] [3].

Neoadjuvant chemoradiotherapy down-sizing of tumour and down-staging of disease reduces local recurrence by up to $50 \%$, facilitating sphincter sparing surgery [1] [3] [4]. Circumferential margin involvement (CRM) involvement is a strong predictor of local recurrence, survival rates. A distal margin of a $1 \mathrm{~cm}$ DRM is adequate [5] [6].

Rudolf Schiessel developed the intersphincteric resection (ISR) followed by hand-sewn coloanal anastomosis technique in 1994, on this basis, an embryonic plane between the viscera and the surrounding skeletal muscles. It was reported to be safe in terms of leakage and mortality. ISR is defined as the ultimate anal preservation surgery by both abdominal and anal approaches which consist of TME and excision of the internal anal sphincter.

Saito et al. reported no differences in the overall survivals and the disease-free survivals between the ISR and the APR groups. There are three types of ISR, a neorectum reservoir allow early preservation of function [7] [8].

Magnetic resonance imaging predicting tumour stage, circumferential resection status, detailed relation between tumour and surrounding anal sphincter complex [3] [8] [9]. Assessment of response is to neoadjuvant treatment [6].

The aim of this paper is to evaluate morbidity, oncologic and functional outcomes after ISR.

\section{Patients and Methods}

\subsection{Nature of Study and Patient Selection}

Between January 2010 and January 2015, we retrospectively collected data on 164 patients with pathologic-proven rectal cancer who underwent ISR at Surgical Oncology Department of South Egypt Cancer Institute, Assiut University, 
Egypt. A complete history and physical examination, CEA levels, full colonoscopy, Pelvi-abdominal MRI/CT and Chest X-Ray were performed. Patients with stage IV rectal cancer were excluded from this study along with those with proved positive surgical margin involved by the tumor and patients undergoing APR for tumors that reached to the DRMs.

\subsection{Neoadjuvant Chemoradiation}

Neoadjuvant chemoradiotherapy for T3 disease or above/presence of pathological nodes, short-course radiotherapy ( $25 \mathrm{~Gy}$; administered as five daily fractions of $5 \mathrm{~Gy}$ ) follow 1 week surgery, or, long-course CRT, patients received 4500 CGy/25 fractions 180 CGy per fraction over 5 weeks \& boost 540 CGy/3 fractions on tumor $+1.5 \mathrm{~cm}$ margin to complete $50.4 \mathrm{~Gy}$ with concurrent chemotherapy concomitant capecitabine ( $825 \mathrm{mg} / \mathrm{m}^{2}$ twice daily), volume included the entire rectum, mesorectum, and presacral space. Axially the volume covered internal iliac LN, perirectal LN, hypogastric LN, and presacral LN (Figure 1). MRI/Surgery performed 6 - 8 weeks after completion of chemoradiotherapy was performed eight weeks.

\subsection{Surgical Technique}

Abdominal part performed either open or laparoscopic technique; high ligation of the inferior mesenteric vein is performed at the level of the inferior border of the pancreas Figure 2(I). Mobilization of the splenic flexure colon, descending colon, Figure 2(J), ligation the inferior mesenteric artery after the emergence of the left colic artery (low tie) Figure 2(L).

TME, with sharp dissection along an anatomic plane between the mesorectal fascia and the fascia of the pelvic sidewall, identify and preserve the pelvic splanchnic nerves Figure 2(M). Denovilliers' fascia is with the exposure of the seminal vesicles and the prostate or the vaginal wall. The dissection was performed as low as possible to the pelvic floor.

The first step of the perineal part of the operation is a good exposition of the anal canal; Saline adrenaline solution was injected sub-mucosally just distal to the dentate line. Figure $2(\mathrm{~N})$ the mucosa and internal sphincter are circumferentially incised facilitates the exposure of the internal sphincter Figure 2(G), total-ISR The internal sphincter is completely removed, subtotal-ISR a two-third resection of the IAS and partial-ISR one-third resection of the upper part of the IAS, The anal orifice is then closed transanally with pursestring sutures Figure 2(P). Dissection was then carried out between internal and external sphincter till the level of pelvic floor. The distal rectal margin were examined with frozen sections, the rectum was removed transanally Figure 2(A).

Restoration of intestinal continuity is achieved with a handsewn coloanal anastomosis Figure 2(K). If enough length Colonic J-pouch about $6 \mathrm{~cm}$ is created, Figure 2(C) transverse coloplasty to create a neorectum Figure 2(D). 

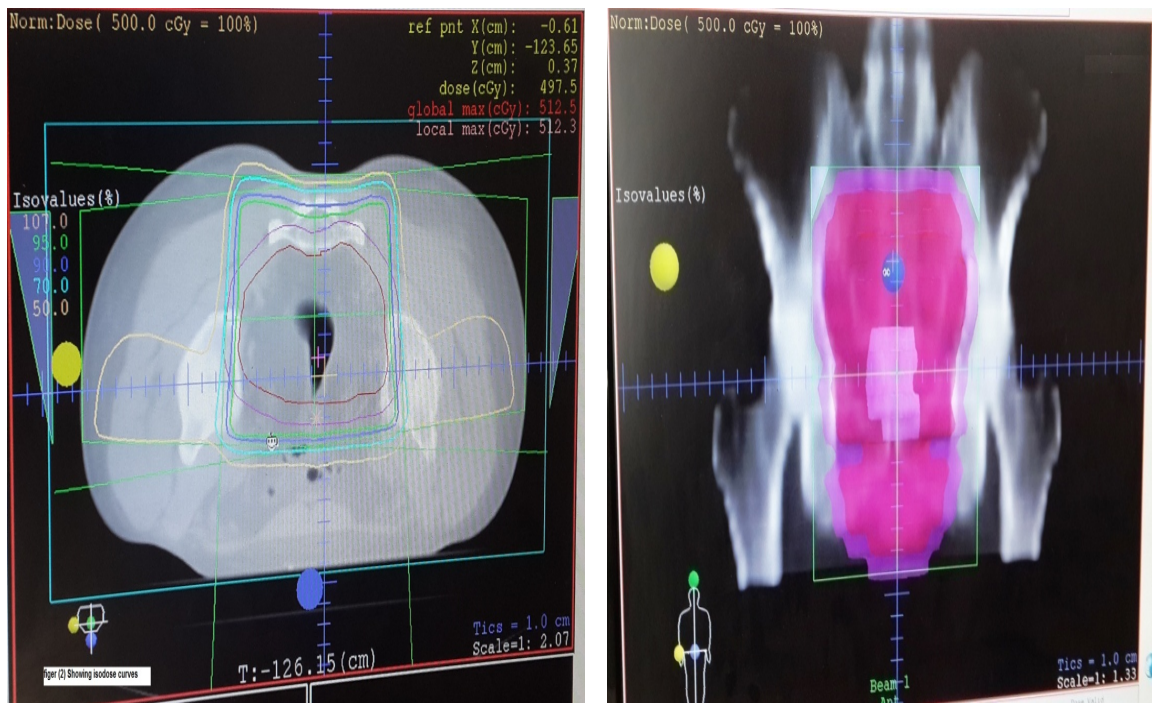

Figure 1. Volume of radiotherapy: Included the entire rectum, mesorectum, and presacral space. Axially the volume covered internal iliac LN, perirectal LN, hypogastric LN, and presacral LN.
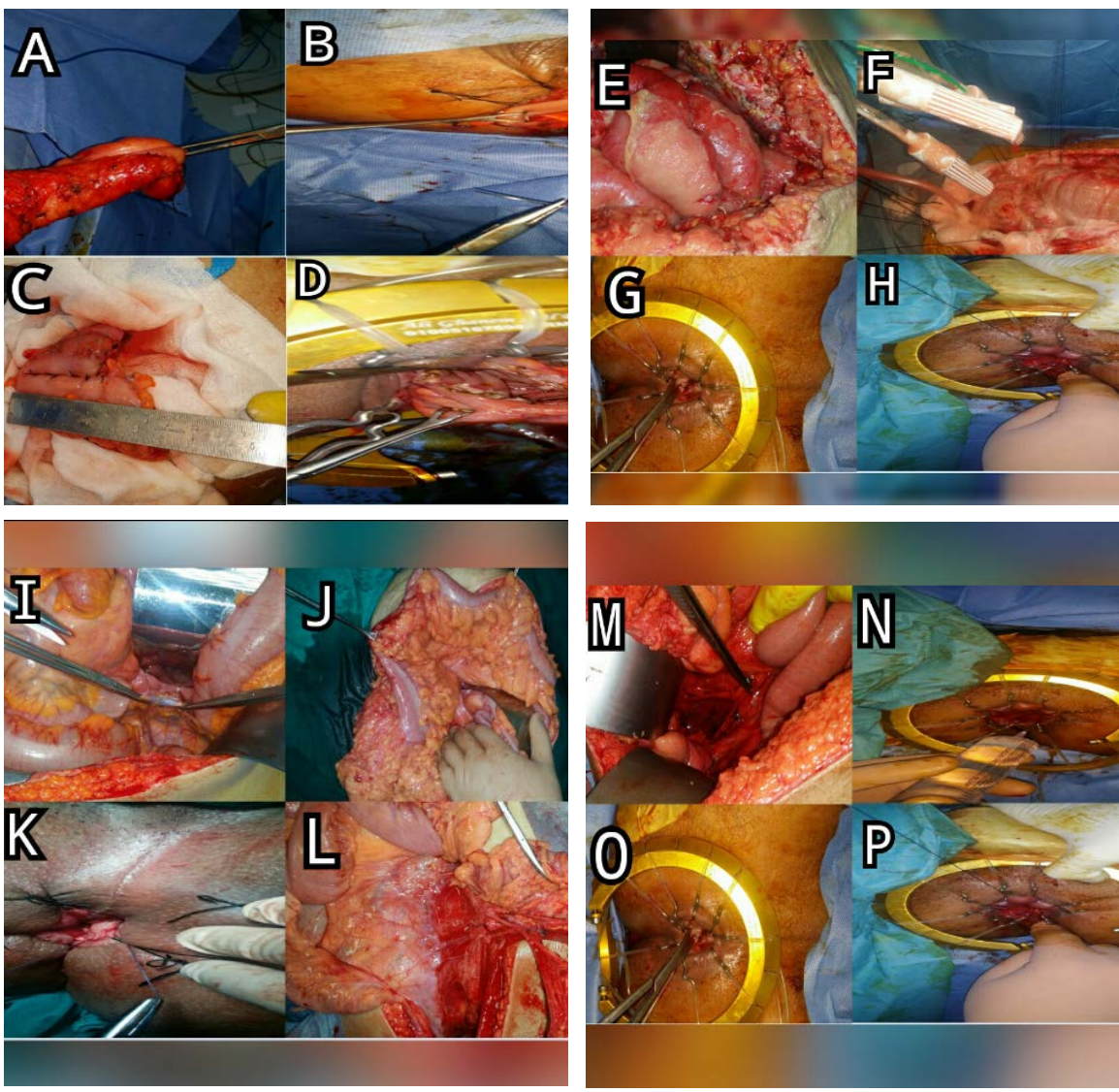

Figure 2. Operative technique.

The side-to-end anastomosis Figure 2(B) preferable over a straight coloanal anastomosis. The temporary diverting ileostomy was performed in selected patients. 


\subsection{Adjuvant Therapy}

Patients with T3, T4, and/or node-positive disease received postoperative adjuvant chemotherapy; FOLFOX was repeated every two weeks for 24 weeks.

\subsection{Statistical Methods}

SPSS (Statistical Package for the Social Science) was used for data management. Mean and standard deviation described quantitative data and counted with percentages for qualitative data. For this retrospective cohort study, data were abstracted from patients' records. Disease-free survival was calculated from the date of curative surgery up to first evidence of either local recurrence of distant metastasis or both. Overall survival was calculated from date of pathologic diagnostic confirmation to date of death or last followed up. For patients who lost follow with advanced state telephone calls were done to assess the occurrence of death. Kaplan Meier methods were used to estimate survival.

\section{Results}

\subsection{Sociodemographic and Clinical Characteristics}

This study included a total number of 164 cases: 92 males and 72 females with a mean age of 54.5 years. Table 1 illustrates sociodemographic and clinical characteristics of the patients. Median follow-up time was of 48 months (range 21 to 120 months). Mean distance from the anal verge to the distal tumour edge was $4.1 \mathrm{~cm}(2.9$ to $6 \mathrm{~cm})$.

\subsection{Operative Data}

The median operation time was 230 minutes (range, 180 to 359 minutes). Median blood loss was $700 \mathrm{~mL}(290-1600 \mathrm{~mL})$, mean postoperative hospital stay was 9 (range 6 - 18) days.

The surgical procedure was performed through a laparotomy in 119 patients (72.6\%) and laparoscopically in 45 patients (27.4\%) cases. Partial resection of the internal sphincter was performed in 60 patients $(36.6 \%)$. Subtotal-ISR in 61 patients (37.2\%) and Total-ISR in 43 patients (26.2\%).

Table 1. Sociodemographic and clinical characteristics of the patients.

\begin{tabular}{cc}
\hline Characteristic & Result \\
\hline Gender (M:F) & $92 \mathrm{M}: 72 \mathrm{~F}$ \\
Age:Mean (Range) & 54.5 years $(21-88)$ \\
Mean Distance from AV & $4.1 \mathrm{~cm}(2.9-6 \mathrm{~cm})$ \\
Neoadjuvant RTH & 147 cases $(89.6 \%)$ \\
Adjuvant Chemotherapy & 115 cases $(70.1 \%)$ \\
Median Follow-Up Time & 48 months $(21-120)$
\end{tabular}

$\mathrm{M}=$ male, $\mathrm{F}=$ female, $\mathrm{AV}=$ anal verge, $\mathrm{RTH}=$ radiotherapy. 
Inferior mesenteric artery ligation was done at the root in 44 patients $(26.8 \%)$ and after left colic artery in 120 patients (73.2\%). Inferior mesenteric vein ligation: High in 160 patients (97.6\%) and Low in 4 patients (2.4\%). The median number of lymph nodes removed at surgery was 17 (range, 9 - 36).

A colonic J-pouch was performed in 27 patients (16.5\%), transverse coloplasty 26 patients (15.9\%), a side-to-end anastomosis 44 patients (26.8\%) and straight coloanal anastomosis 67 patients $(40.9 \%)$. Protective ileostomy was performed for 11 patients $(6.7 \%)$.

\subsection{Post-Operative Morbidity \& Management}

Two deaths (1.2\%) occurred, one due to myocardial infarction, one patient who had anastomotic leakage and sepsis Figure 2(E).

Surgical Morbidity were observed in 24 patients (14.6\%). Anastomotic leakage occurred in 6 patients (3.7\%) \{Four patients $(2.4 \%)$ were treated conservatively and two patients $(1.2 \%)$ were managed by abdominal drainage and diverting stoma\}. Pelvic abscess occurred in 6 patients $(3.7 \%)$ who were treated by percutaneous drainage.

Anastomotic stenosis were observed 3 patients (1.8\%) \{One need a Hegar dilator, second underwent endoscopic balloon dilatation, third underwent surgery (colostomy)\}.

Wound infection and hernia in 5 patients (3\%) and respiratory tract infection in 2 patients $(1.2 \%)$.

Ileus (bowel obstruction) was observed in 5 patients (3\%) who were managed conservatively. Anal irritation occurred in 23 patients (14\%). Four female patients (2.4\%) developed a recto-vaginal fistula: \{one was managed conservatively and the other 3 had a defunctioning ileostomy, a revisional coloanal anastomosis repair and omental flap\} (Figure 3).

Transient voiding difficulty 6 patients (3.7\%), erectile dysfunction 24 patients (14.6\%), ejaculatory dysfunction 25 patients (15.2\%).

\subsection{Oncologic Outcomes}

Pathologic complete response 18 patients (11\%). The median tumor size was 34 $\mathrm{mm}$ (range 28 - $56 \mathrm{~mm}$ ).

Neoadjuvant radiotherapy provided to 147 patients (89.6\%) \{long-course radiotherapy 122 patient (74.4\%), short-course radiotherapy 25 patients (15.2\%)\}, neoadjuvant chemotherapy 47 patients (28.7\%). Adjuvant Chemotherapy in 115 patients (70.1\%).

Median circumferential margin was $7 \mathrm{~mm}(1-19 \mathrm{~mm})$. Positive in four patients (2.4\%). The distal margin median $20 \mathrm{~mm}(8-40 \mathrm{~mm})$, complete resection (R0) was achieved for 156 patients (95.1\%).

Local recurrence rate was observed in 13 patients (7.9\%), in \{pelvic wall 3 patients $(1.8 \%)$ treated by pelvic lymphadenectomy, anastomoticin 4 patients (2.4\%) (managed with abdominoperineal resection), urinary bladder in 3 


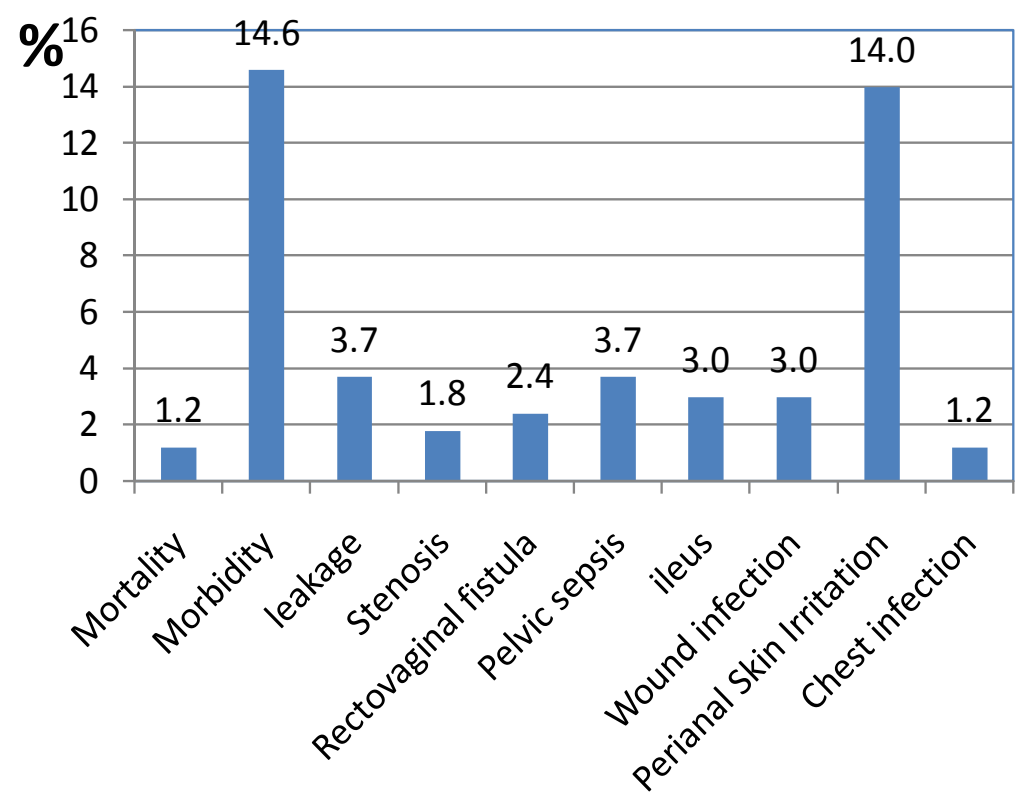

Figure 3. Chart of post-operative complications.

patients $(1.8 \%)$, seminal vesicle in 1 patient $(0.6 \%)$ and presacral area in 2 patients (1.2\%). Recurrence was treated by curative pelvic exenteration\}.

Distant metastasis 25 patients (15.2\%); \{peritoneal dissemination in 2 patients (1.2\%) cytoreductive surgery and hyperthermic intraperitoneal chemotherapy (HIPEC) for peritoneal carcinosis Figure $2(\mathrm{~N})$, oxaliplatin given bidirectionally with 5-FU intravenously and oxaliplatin in the peritoneum, $460 \mathrm{mg} / \mathrm{m}^{2}$ for 30 min at $42^{\circ} \mathrm{C}-43^{\circ} \mathrm{C}+$ I.V. 5 -FU $400 \mathrm{mg} / \mathrm{m}^{2}$ \& leucovorin $20 \mathrm{mg} / \mathrm{m}^{2}$ for peritoneal carcinosis (liver, $10(6 \%)$ ); 6 (3.6\%) partial hepatic resection for liver metastases, non-regional nodes $3(1.8 \%)$, lung $5(3 \%)$, ovary 1 patient $(0.6 \%)$, bone 4 patients $(2.4 \%)$, whereas the other patients were treated by palliative chemotherapy (2nd line FOLFIRI)\}.

The 5-year overall and disease-free survival rates were $79.8 \%$ and $75.8 \%$, respectively.

\subsection{Functional Results (Twelve Months after Surgery)}

Incontinence was assessed by calculating the Wexner score, where 0 reflected perfect continence and 20 reflected the worst possible level of incontinence the median Wexner score $6(1-18)$. Incontinence ffor flatus 18 patients $(11 \%)$, to liquid in 8 patients $(4.9 \%)$, to solid in 7 patients $(4.3 \%)$ \}. Median number of bowel motions in a 24 -h period was $3(1-10)$. Faecal urgency was present $(<15$ min) 29 patients $(17.7 \%)$. Stool fragmentation 31 patients (18.9\%). Difficult evacuation occurred in 29 patients (17.7\%). Lifestyle alteration 24 patients (14.6\%). Difficulty feces/flatus discrimination 71 patients (43.3\%). Nocturnal soiling in 28 patients (17.1\%). Daytime soiling 18 patients (11\%). Pad wearing 39 Patients (23.8\%). Anti-diarrhea medication loperamide 23 patients (14\%) (Figure 4). 


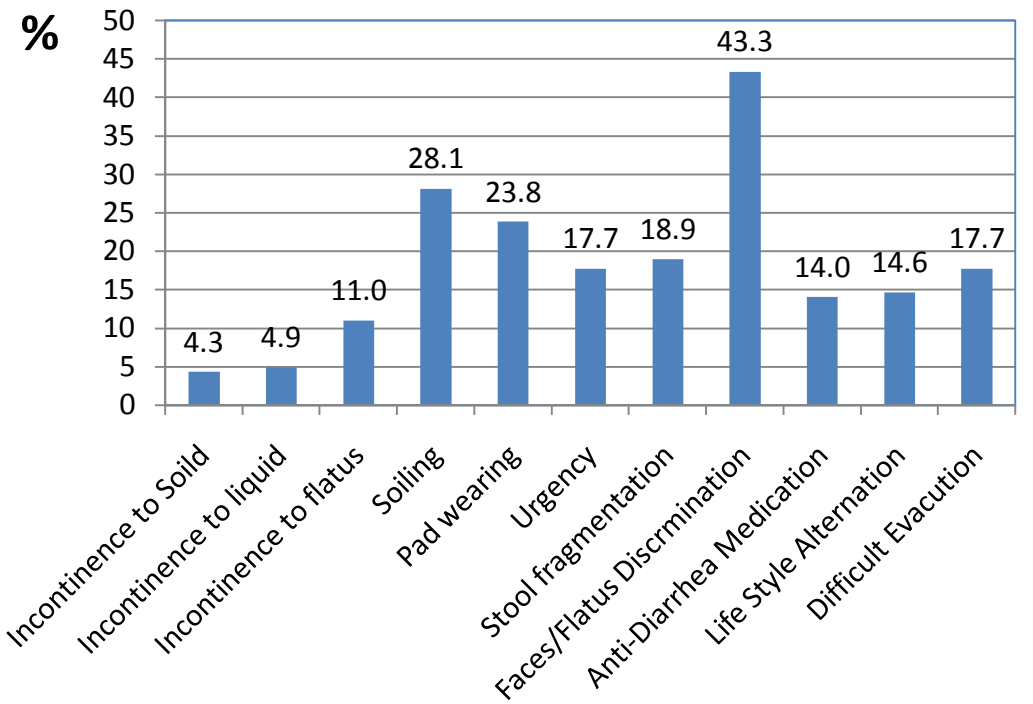

Figure 4. Chart of functional outcome.

\section{Discussions}

Swedish Rectal Cancer trial, neoadjuvant radiation was associated with a $21 \%$ survival benefit and $60 \%$ reduction in local recurrence [10], The Dutch Colorectal Cancer Group Trial from $10.1 \%$ to $3.4 \%$ [11] tumor down staging in $40 \%$ increases R0 resection, Rullier et al. complete microscopic resection (R0) was $89 \%$ [12], increases the chances and facilitate sphincter preserving surgery in $80 \%$ owing to tumour shrinkage [13]. Schiessel et al. pathological complete response $8 \%$ to $30 \%$ [14]. In our study, $89.6 \%$ underwent neoadjuvant radiotherapy, long-course radiotherapy (74.4\%), short-course radiotherapy $15.2 \%$, neoadjuvant chemotherapy, $28.7 \%$ ), adjuvant chemotherapy in $70.1 \%$, pathologic complete response (11\%). Complete resection (R0) was achieved for (95.1\%).

Martin et al. the 5-year disease-free survival rate was $78.6 \%$ and the 5-year overall survival was $86.3 \%$ [15]. Oncological outcomes after ISR were not markedly different from those after APR with ranges of $68 \%-86 \%$ and $76 \%-97 \%$, respectively. In our study, 5-year overall survival was $79.8 \%$ with 5 -year disease-free survival (DFS) being $75.8 \%$.

Akasu et al. confirmed the long-term oncologic safety of ISR in low rectal cancer, local recurrence rate after ISR was $5.7 \%$ and systematic recurrence rate $11 \%$, compared to $6 \%-9 \%$ and $14 \%$ respectively after LAR/APR [13]. A negative CRM was achieved in 96\% [6], Vernava et al. no differences in the 5-year recurrence or CSS rate between rectal cancer patients with DRM $\leq 1 \mathrm{~cm}$ and those with DRM $>1 \mathrm{~cm}$. In our study the local recurrence rate was (7.9\% patients) Distant metastasis (15.2\%). A negative CRM (97.6\%), distal margin median 20 $\mathrm{mm}$.

Perfusion of the bowel stumps is risk factors for anastomotic leakage. Inferior mesenteric artery ligation at the root (39\%), after left colic artery (61\%). Inferior mesenteric vein ligation: High in (39\%) and low in (61\%), the median number of lymph nodes removed at surgery was 29. The median tumour size was 3.7 [9] 
[16]. In our series, high ligation of the inferior mesenteric artery $26.8 \%$ only in palpable proximal mesenteric lymph nodes, failure sigmoid colon to be easily drawn toward the anus. The mean number of lymph nodes harvested was 17; low arterial tie in $73.2 \%$ the median tumour size was $34 \mathrm{~mm}$.

According to the study of Yamada et al, the patients are consisted of the following: partial ISR 69; subtotal - ISR 16; total ISR 19. The extent of ISR does not significantly affect general quality of life, but it adversely affects faecal continence [17]. In our study underwent (partial 60, subtotal-ISR in 61, total-ISR in 43) patients.

Schiessel et al. showed that although no evidence that a protective stoma prevents anastomotic leakage, but reduce the impact of leakage the need for reoperation. ISR can be carried out safely without defunctioning stoma [18]. Diverting stoma was performed in 19\% [19]. In the present study, protective ileostomy was performed for $6.7 \%$ patients only.

Straight coloanal anastomosis was first reported in 1982 by Parks with poor functional results, the colonic J pouch was introduced by Lazorthes technically possible of patients (95\%). Better functional results not sustained beyond 2 years. Transverse coloplasty was designed by Z'graggen et al. in patients with bulky colonic mesentery and narrow pelvis with comparable functional results [3] [10] [13] [20]. Baker-style side-to-end anastomosis is an easier way for reconstruction [13] [21]. In our study a colonic J-pouch 16.5\%, Transverse coloplasty $15.9 \%$, a side-to-end anastomosis $26.8 \%$ and straight coloanal anastomosis. $40.9 \%$.

Tinley and Tekkis: Perioperative mortality of ISR was $1.6 \%$, morbidity rate of $25.8 \%$, (anastomotic leak rate $10.5 \%$, postoperative obstruction rate 5\% (8.3\%).) developed a recto-vaginal fistula [22], the pelvic sepsis rate was of $2.4 \%$, wound infection 9\% [2] [7]. Schiessel and colleagues [12]: 1\% benign anastomotic stricture ranging from $2.5 \%$ to $19.5 \%$ [23]. In our study, Operative mortality, $(1.2 \%)$ surgical morbidity (14.6\%) anastomotic leakage (3.7\%) and pelvic abscess $(3.7 \%)$ wound infection (3\%), respiratory tract infection $(1.2 \%)$, ileus $(3 \%)$, anal irritation (14\%), a recto-vaginal fistula $(2.4 \%)$.

Kuo et al. reported functional outcomes of ISR $38 \%$ had stool fragmentation, $23.8 \%$ had nocturnal defecation Saito et al. mean Wexner score was 7.8. Kohler et al: Incontinence to flatus $23.8 \%$, incontinence for liquid $29 \%$ and for solid stool 3.7\%, Schiessel et al. the mean stool frequency per $24 \mathrm{~h}$ was 2.6, Martin's et al. [15] use of antidiarrheal medications (30\%), Denost 7 urgency in 38\%, Yoo et al. use of hygiene pads (20\%) [2] [7] [8] [13] [21]. In our study, the median Wexner score was 6 . Incontinence for flatus $11 \%$, to liquid $4.9 \%$, to solid $4.3 \%$. Median number of bowel motions in a 24-h period was 3, Faecal urgency was present $17.7 \%$, Stool fragmentation $18.9 \%$, Nocturnal soiling $17.1 \%$, pad wearing 23.8\%. Anti-diarrhea medication loperamide $14 \%$.

Abdominoperineal resection might be more hazardous to erectile function than ISR Ho et al.: Sexual dysfunction varied from $23 \%$ - 69\% urinary complica- 
tions, erectile and ejaculatory dysfunction occurred in $19.2 \%$ and $29.8 \%$ of male patients [3] [21]. In our study Transient voiding difficulty 3.7\%, erectile dysfunction $14.6 \%$, ejaculatory dysfunction occurred in $15.2 \%$.

\section{Conclusion}

Intersphincteric resection (ISR) is a feasible, effective, safe and valuable procedure with acceptable oncologic and functional outcomes for sphincter saving approach in selected patients with distal rectal carcinomas.

\section{Acknowledgements}

Authors thank Dr. Mohamed Ismail Omar, M.Sc. for his sincere effort in grammar review of the present manuscript and drafting of the manuscript template.

\section{Conflicts of Interest}

The authors declare no conflicts of interest regarding the publication of this paper.

\section{References}

[1] Mulsow, J. and Winter, D.C. (2011) Sphincter Preservation for Distal Rectal Cancer-A Goal Worth Achieving at All Costs? World Journal of Gastroenterology, 17, 855-861. https://doi.org/10.3748/wjg.v17.i7.855

[2] Rullier, E., et al. (2001) Preoperative Radiochemotherapy and Sphincter-Saving Resection for T3 Carcinomas of the Lower Third of the Rectum. Annals of Surgery, 234, 633-640. https://doi.org/10.1097/00000658-200111000-00008

[3] Benjamin, D. and Ceelen, W. (2015) Oncological and Functional Outcome of Intersphincteric Resection and Coloanal Anastomosis for Very Low Rectal Cancer. University Ghent, Belgium.

[4] Shirouzu, K., Murakami, N. and Akagi, Y. (2017) Intersphincteric Resection for Very Low Rectal Cancer: A Review of the Updated Literature. Annals of Gastroenterological Surgery, 1, 24-32. https://doi.org/10.1002/ags3.12003

[5] Bernstein, T.E., et al. (2012) What Is a Safe Distal Resection Margin in Rectal Cancer Patients Treated by Low Anterior Resection without Preoperative Radiotherapy? Colorectal Disease, 14, e48-e55. https://doi.org/10.1111/j.1463-1318.2011.02759.x

[6] Krishnamurty, M.D. and Wise, P.E. (2016) Importance of Surgical Margins in Rectal Cancer. Journal of Surgical Oncology, 113, 323-332. https://doi.org/10.1002/jso.24136

[7] Martin, S.T., Heneghan, H.M. and Winter, D.C. (2012) Systematic Review of Outcomes after Intersphincteric Resection for Low Rectal Cancer. British Journal of Surgery, 99, 603-612. https://doi.org/10.1002/bjs.8677

[8] Scala, D., et al. (2016) Laparoscopic Intersphincteric Resection: Indications and Results. Updates in Surgery, 68, 85-91. https://doi.org/10.1007/s13304-016-0351-6

[9] Hohenberger, W., et al. (2006) The Influence of Abdomino-Peranal (Intersphincteric) Resection of Lower Third Rectal Carcinoma on the Rates of Sphincter Preservation and Locoregional Recurrence. Colorectal Disease, 8, 23-33. https://doi.org/10.1111/j.1463-1318.2005.00839.x

[10] Oiyama, Y., et al. (2017) Complete Laparoscopic Total Mesorectal Excision with an 
Intersphincteric Resection and Coloplasty Pouch Anal Anastomosis for Lower Rectal Cancer. Journal of the Anus, Rectum and Colon, 1, 35-38.

[11] Gerard, J.P., et al. (2004) Improved Sphincter Preservation in Low Rectal Cancer with High-Dose Preoperative Radiotherapy: The Lyon R96-02 Randomized Trial. Journal of Clinical Oncology, 22, 2404-2409.

https://doi.org/10.1200/JCO.2004.08.170

[12] Ludwig, K.A. (2007) Sphincter-Sparing Resection for Rectal Cancer. Clinics in Colon and Rectal Surgery, 20, 203-212. https://doi.org/10.1055/s-2007-984864

[13] Komborozos, V.A. (2011) Intersphincteric Resection for Low Rectal Cancer. Hellenic Journal of Surgery, 83, 72-80.

[14] Murad-Regadas, S.M., et al. (2011) Criteria for Three-Dimensional Anorectal U1trasound Assessment of Response to Chemoradiotherapy in Rectal Cancer Patients. Colorectal Disease, 13, 1344-1350. https://doi.org/10.1111/j.1463-1318.2010.02471.x

[15] Dimitriou, N., et al. (2015) Low Rectal Cancer: Sphincter Preserving Techniques-Selection of Patients, Techniques and Outcomes. World Journal of Gastrointestinal Oncology, 7, 55-70. https://doi.org/10.4251/wigo.v7.i7.55

[16] Cassinotti, E., et al. (2017) Transanal Total Mesorectal Excision (TaTME): Tips and Tricks of a New Surgical Technique. Annals of Laparoscopic and Endoscopic Surgery, 2, 8 p. https://doi.org/10.21037/ales.2017.05.07

[17] Barisic, G., et al. (2011) Function after Intersphincteric Resection for Low Rectal Cancer and Its Influence on Quality of Life. Colorectal Disease, 13, 638-643. https://doi.org/10.1111/j.1463-1318.2010.02244.x

[18] Lee, S.I., Sohn, S.K. and Park, Y.A. (2007) Sphincter-Preserving Operations without Defunctioning Stoma. ANZ Journal of Surgery, 77, 381-384. https://doi.org/10.1111/j.1445-2197.2007.04066.x

[19] Koyama, M., et al. (2014) Long-Term Clinical and Functional Results of Intersphincteric Resection for Lower Rectal Cancer. Annals of Surgical Oncology, 21, 422-428. https://doi.org/10.1245/s10434-014-3573-1

[20] Akasu, T., et al. (2008) Intersphincteric Resection for Very Low Rectal Adenocarcinoma: Univariate and Multivariate Analyses of Risk Factors for Recurrence. Annals of Surgical Oncology, 15, 2668-2676. https://doi.org/10.1245/s10434-008-0047-3

[21] Cipe, G., et al. (2012) Intersphincteric Resection and Coloanal Anastomosis in Treatment of Distal Rectal Cancer. International Journal of Surgical Oncology, 2012, Article ID: 581258. https://doi.org/10.1155/2012/581258

[22] Tekkis, P., et al. (2015) Hand-Sewn Coloanal Anastomosis for Low Rectal Cancer: Technique and Long-Term Outcome. Colorectal Disease, 17, 1062-1070. https://doi.org/10.1155/2012/581258

[23] Lee, S.Y., Kim, C.H., Kim, Y.J. and Kim, H.R. (2018) Anastomotic Stricture after Ultralow Anterior Resection or Intersphincteric Resection for Very Low-Lying Rectal Cancer. Surgical Endoscopy, 32, 660-666. https://doi.org/10.1007/s00464-017-5718-3 